Surnmary The amount of light reflected from a retroreflective traffic sign decreases with an increase in the observation angle-the angle between the headlamp, the sign, and the eyes of the driver. Mainly because of the increased seated eye height of truck drivers, the actual observation angles are greater for them than they are for car drivers. Consequently, there is concern about the impaired night-time detection and legibility of retroreflective signs for truck drivers. The present study evaluated the relative amount of light reaching drivers of different types of vehicle by using survey data collected in 1989 by the Transport and Road Research Laboratory (TRRL) in England. The TRRL data included driver eye heights and headlamp mounting heights for 445 vehicles. The present analysis considered three sign locations on a straight roadway: left shoulder, centre, and right shoulder. Two viewing distances were included: $152 \mathrm{~m}$ (500 feet) (typical of a sign-legibility distance), and $305 \mathrm{~m}$ ( 1000 feet) (typical of a sign-detection distance). The analysis considered both the differential amount of illumination impinging on the signs from headlamps of trucks and cars, as well as the differential amount of the light reflected from the signs in the direction of truck drivers and car drivers. The main results are that for the viewing distance of $152 \mathrm{~m}$, the amount of light reaching a truck driver can be as low as $25 \%$ of the light reaching a car driver; the corresponding percentages for the viewing distance of $305 \mathrm{~m}$ are as low as $68 \%$. These reductions were then related to the expected effects on sign legibility and detection. The results imply that the increased eye height of truck drivers could have a major effect on the legibility of retrorefiective traffic signs, but only a modest effect on their detection.

\title{
Influence of truck driver eye position on effectiveness of retroreflective traffic signs
}

\author{
Mivak PhD, Mlannagan PhD and $\mathrm{A} W$ Gellatly \\ The University of Michigan Transportation Research Institute, 2901 Baxter Road, Ann Arbor, Michigan 48109-2150, USA
}

Received 20 February 1992, in final form 20 July 1992

\section{Introduction}

At the increased seated height of truck (lorry) drivers, the night-time brightness of retroreflective traffic signs is adversely affected, and consequently their detection and legibility are diminished. This problem arises because retroreflective materials reflect light back towards the source of illumination in a narrow cone, with the highest intensity near the centre of the cone along the axis of illumination. In the traffic situation this means that retroreflective signs are most efficient at reflecting light directly back to the headlamps. For car drivers this is close to optimal, since the observation angles formed by the locations of the drivers' eyes, traffic signs, and headlamps are relatively small. Because of increased seated eye height, these angles are somewhat larger for truck drivers. Consequently, the amount of light reflected back to the eyes of a truck driver is substantially less than to the eyes of a car driver. While the preceding is not a new argument ${ }^{(1)}$, we are not aware of any quantiative evaluation of the ragnnitude of the problem. The present study was designed to provide such an evaluation.

An addicional relevant factor is the nounting height of headlarnps. In seaeral, the headlamps of trucks are mounted higher than those of cars. This usualiy leads to more light incident on the sign from trucks than from cars, although not enough to negate the effect of increased eye height on observation angle. Nevertheless, the present analysis took this difference into account.

The primary data for the present analysis were individual driver eye heights and headlamp mounting heights obtained by $\mathrm{Cobb}^{(2)}$ for a sample of 452 vehicles in England that included cars and trucks. The analysis involved the following steps, each performed for each vehicle type, two selected viewing distances, left and right headlamp, three mounting positions of traffic signs, and a typical retrorefiective sign material:

(a) Calculate the angular location of the sign with respect to the headlamp.

(b) Using this angular information, estimate the relative amount of headlamp illumination incident on the sign.

(c) Calculate the observation angle.

(d) Using this observation angle and the retroreflective capability of a typical sign material, estimate the relative amount of light reflected towards the eyes of the driver for each headlamp.

(e) Using the relative amounts of incident and reflected light, obtain the total light reaching the eyes of the driver.

\section{Applicability of Cobb's data to the US situation}

The data from $\mathrm{Cobb}^{(2)}$ are appropriate for the present purpose, since they contain joint measurements of two variables of interest-driver eye height and headlamp mounting height-for each observed vehicle. Other potencially relevane stydiss ${ }^{(3-5)}$ measured only drityer eye height. Since of primary interest in this scudy were the implications for the situation in the US, we performed two analyses to address the potential concern that the English vehicle population studied by $\mathrm{Cobb}^{(2)}$ might be substantially different from the US vehicle population. The first analysis compared selected percentile values for car driver eye heights in $\mathrm{Cobb}^{(2)}$ with the corresponding estimates for the 1981 US car population reported by Olson $e t a l_{0}{ }^{(5)}$. This comparison shows a reasonable similarity berween the two sets of data. For example, Olson et al. estimated that the eye height of $106.7 \mathrm{~cm}$ corresponds 
to the 25th percentile, while Cobb's 25th percentile is $110.0 \mathrm{~cm}$. Similarly, Olson et al. estimated that the eye height of $114.3 \mathrm{~cm}$ corresponds to the 79 th percentile, while Cobb's 75 th percentile is $115.5 \mathrm{~cm}$. The second analysis compared the ranges of headlamp mounting heights reported by Cobb for all vehicles with the current US mounting height requirements ${ }^{(6)}$. Again, there is reasonable correspondence between these two sets of data. Cobb's headlamp mounting heights range from $55 \mathrm{~cm}$ to $120 \mathrm{~cm}$, compared to the US limits of $55.9 \mathrm{~cm}$ and $137.2 \mathrm{~cm}$.

\section{Relevant aspects of retroreflection}

The amount of light reaching an observer from a retroreflective sign at a given distance depends on the amount of light incident on the sign, and the efficiency of the sign material to reflect light in the direction of the observer. The present analysis took into account both of these factors.

\subsection{Incident light}

Because of differences in mounting height of headlamps, a different part of the same headlamp beam, when mounted on a truck as opposed to a car, is directed towards a given point in space. To the extent that truck lamps are mounted higher, the amount of light reaching the sign might be greater for trucks. We evaluated this effect by:

(a) calculating, for each vehicle, the angular location of selected sign positions relative to the headlamp, and

(b) using this angular information, estimating the amount of headlamp illumination incident on the sign from US-type low beams.

This analysis was performed for each headlamp, and for each sign position.

\subsection{Retroreflective efficiency}

The retroreflectance of a given material towards a given point in space depends on its inherent efficiency and the geometry between the headlamp, the sign, and the observer. This geometry is characterised by a set of angles, including observation, entrance, rotation, presentation, and viewing angles ${ }^{(7)}$. However, for the traffic situations of interest in the present study (involving straight roadway and small entrance angles), observation angle is of dominant importance. The observation angle, in our situation, is the angle formed by the headlamp, the sign, and the eyes of the driver (i.e. the angle between the illumination axis and the observation axis). The observation angle must be quite small (preferably $0.5^{\circ}$ or less) for presently availatble retroreflective materials to function effectively. We calculared the observarion angle for each venicle, headlamp, viewing distance, and sign position, and used this information to estimate the relative amount of light reflected towards the eyes of the driver.

\section{Method}

\subsection{Primary data}

The primary data for this study-driver eye heights and headlamp mounting heights-came from a vehicle lighting survey performed in 1989 by TRRL. (Transport and Road Research Laboratory) in England and reported by $\mathrm{Cobb}^{(2)}$. Cobb's report contains percentile information; raw data for the individual vehicles were provided to us by TRRL.

The survey involved measuring light sutput from all signaling lamps, aim of low-beam headlights, their output in two directions, as well as driver eye height and headlamp mounting height. The sample of " 452 vehicles consisted of 178 cars (including 11 car-derived vans), 86 light goods vehicles (including 2 minibuses and 1 ambulance), 94 rigid heavy goods vehicles (including 2 coaches) and 94 articulated vehicles' ( $p$ 5). The survey was conducted at several sites in southern England. The vehicles at these sites were selected at random, but participation was voluntary.

We relabeled the light goods vehicles as light trucks and we combined heavy goods vehicles with articulated vehicles to form a group labeled heavy trucks. Of the 452 vehicles in Cobb's study, 445 were measured for both headlamp mounting height and driver eye height. Consequently, these 445 vehicles ( 165 cars, 94 light trucks, and 188 heavy trucks) constituted the sample in the present study.

\subsection{Additional vehicular data}

The observation angle depends not only on the headlamp mounting height, driver eye height, and sign position, but also on the lateral and longitudinal separations of driver eye position and headlamps. These dimensions were not included in the survey by Cobb. Consequently, in our calculations we used these dimensions as parameters that depended on the type of the vehicle. These parameters (see Table 1) were selected to be reasonable values for current US fieets.

\subsection{Effect of observation angle on retroreflectivity}

Table 2 lists typical data relating observation angle to the amount of retroreflected light for the entrance angle of -4 . The information in Table 2 is encapsulated lens material. (Another commonly used material-enclosed lens- is an inherently less efficient retrozeflector, typically about one third as efficient as encapsulated lens material. However, both materials are highly sensitive to observation angle, but relatively insensitive to entrance anglif). The information on the efect of observation angle was provided to us by a sign manufacturer (see

Table 1 Parameter values in present calculations

\begin{tabular}{llll}
\hline Vehicle group & $\begin{array}{l}\text { Lateral separation berween } \\
\text { left lamp and driver } \\
\text { eyes (cm) }\end{array}$ & $\begin{array}{l}\text { Lateral separation berween } \\
\text { right lamp and driver } \\
\text { eyes (cm) }\end{array}$ & $\begin{array}{l}\text { Longitudinal separation } \\
\text { between lamps and } \\
\text { driver eyes (cm) }\end{array}$ \\
\hline Cars & 15 & 99 & 206 \\
Light trucks & 18 & 112 & 206 \\
Heavy trucks & 30 & 168 & 152 \\
\hline
\end{tabular}


Table 2 Relative reflectance as a funcrion of observation angle for encapsulated lens material at an enurance angle of $-4^{\circ}$ (typical values obtained by averaging normalised data for the seven standard colours)

\begin{tabular}{ll}
\hline $\begin{array}{l}\text { Observation } \\
\text { angle }()\end{array}$ & $\begin{array}{l}\text { Relative } \\
\text { reflectance }\end{array}$ \\
\hline 0.10 & 1.000 \\
0.15 & 0.946 \\
0.20 & 0.875 \\
0.25 & 0.792 \\
0.30 & 0.699 \\
0.35 & 0.604 \\
0.40 & 0.509 \\
0.45 & 0.420 \\
0.50 & 0.340 \\
0.55 & 0.269 \\
0.60 & 0.211 \\
0.65 & 0.165 \\
0.70 & 0.131 \\
0.75 & 0.107 \\
0.80 & 0.091 \\
0.85 & 0.082 \\
0.90 & 0.077 \\
\hline
\end{tabular}

Acknowledgements) for each of the seven standard traffic-sign colours. The data for each colour were then normalised by setting the amount of reflected light for an observation angle of $0.1^{\circ}$ to 1 . Since all colours showed similar normalised angular effects, the normalised data for the seven colours were then averaged to produce the information in Table 2. This information indicates, for example, that if the coefficient of retroreflection at observation angle $0.2^{\circ}$ is $300 \mathrm{~cd} \mathrm{lux}^{-1} \mathrm{~m}^{-2}$ (a typical value for a Class $I^{(8)}$ white encapsulated lens), then the corresponding coefficient of retroreflection at observation angle of $0.9^{\circ}$ is only $26.4 \mathrm{~cd} \mathrm{lux} \mathrm{m}^{-2}(300 \times 0.077 / 0.875)$.

\subsection{Sign positions}

Three standard sign positions (right shoulder, centre, and left shoulder) were used in the present calculations (see Figure 1). They all involved a straight, flat, two-lane roadway. These three sign positions were used as typical in recent studies $(9,10)$.

\subsection{Viewing distances}

We considered two viewing distances: $152 \mathrm{~m}$ and $305 \mathrm{~m}$ (500 and 1000 feet). The shorter distance was selected as a reasonable legibility distance for traffic signs, while the longer distance as a reasonable detection distance.

\subsection{Headlamp illumination}

The present calculations used a luminous-intensity matrix of a US low-beam headlamp (Westinghouse No. 6014) that was used in previous studies on legibility of traffic signs ${ }^{(9.10)}$. The luminous intensities were based on a new and clean headlamp. (Dirt can reduce the light output by up to $50 \%{ }^{(2)}$.) The isocandela diagram of this headlamp is shown in Figure 2. The luminous intensity values were available in half-degree steps. Interpolation was used to derive the intensity of the actual angles of interest. The same low-beam matrix was used for all types of vehicles.

\section{Results}

This section summarises the relevant data from $\mathrm{Cobb}^{(2)}$ and presents a step-by-step analysis of the amount of light reaching a driver who is either $152 \mathrm{~m}$ or $305 \mathrm{~m}$ from the sign.

The data from $\mathrm{Cobb}^{(2)}$ on headlamp mounting height and driver eye height are summarised in Tables 3 and 4 . The subsequent calculations are based on the mean data.

Table 3 Headlamp mounting height to the centre of the lens (m) from $\operatorname{Cobb}^{(2)}$

\begin{tabular}{lllll}
\hline Vehicle group & \multicolumn{3}{c}{ Headlamp mounting height $(\mathrm{m})$} \\
\cline { 2 - 5 } & Mean & Minimum & Maximum & $\begin{array}{l}\text { Standard } \\
\text { deviation }\end{array}$ \\
\hline Cars & 0.62 & 0.55 & 0.83 & 0.04 \\
Light trucks & 0.76 & 0.56 & 0.95 & 0.09 \\
Heavy trucks & 0.85 & 0.57 & 1.20 & 0.11 \\
\hline
\end{tabular}

Table 4 Driver eye height (m) from $\mathrm{Cobb}^{(2)}$

\begin{tabular}{lllll}
\hline Vehicle group & \multicolumn{3}{c}{ Driver eye height $(\mathrm{m})$} \\
\cline { 2 - 5 } & Mean & Minimura & Maximum & $\begin{array}{l}\text { Standard } \\
\text { deviation }\end{array}$ \\
\hline Cars & & & 0.08 \\
Light trucks & 1.14 & 1.00 & 1.58 & 0.23 \\
Heavy trucks & 2.33 & 1.07 & 2.23 & 0.17 \\
\hline
\end{tabular}

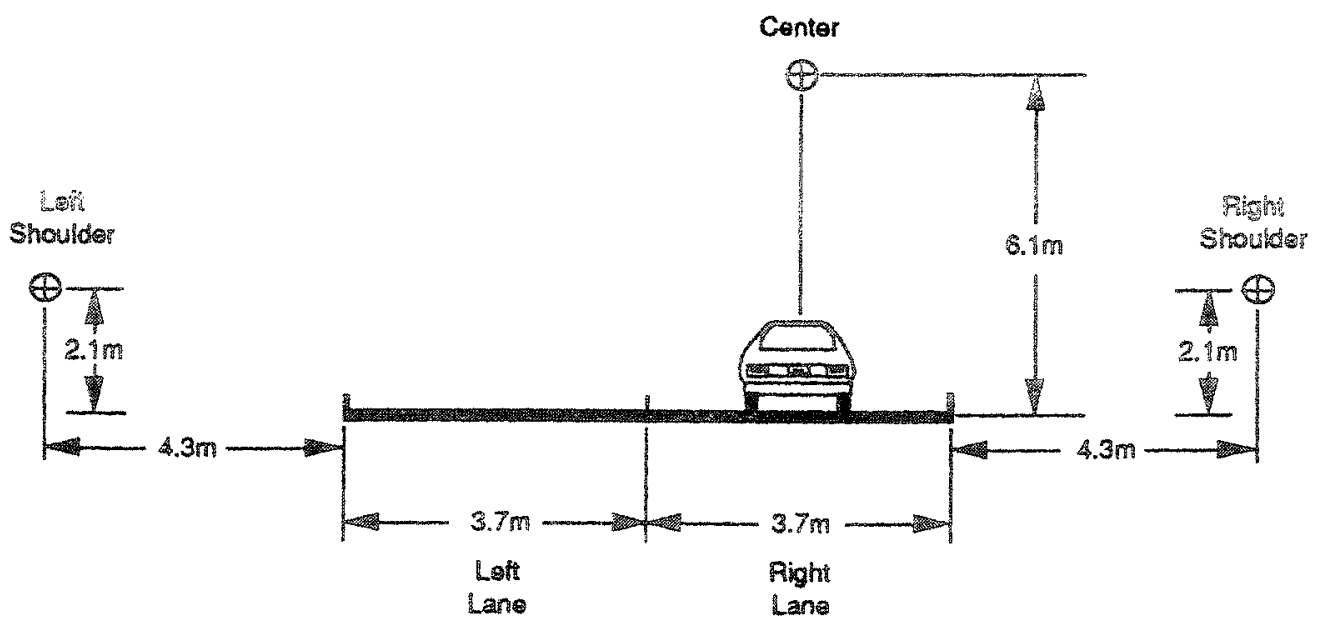

Figure 1 Schematic representation (not to scale) of the sign positions (after Wolman and Szczech ${ }^{(9)}$ ) 


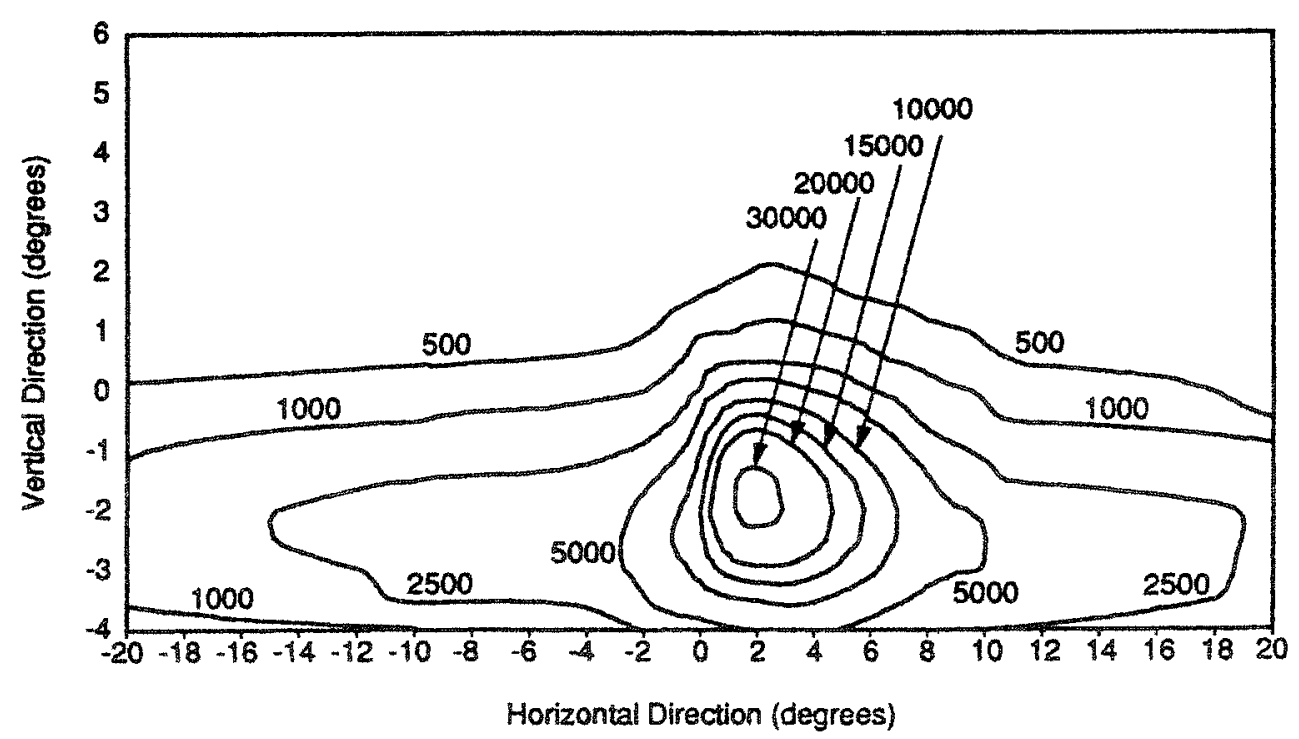

Figure 2 Isocandela diagran of the headlamp used in the calculations

\subsection{Consequences for a viewing distance of $152 \mathrm{~m}$}

(a) Incident light on signs: The mean angular location of each sign (with respect to the headlamp) is described in Table 5 for each vehicle group. This information, along with an intensity matrix for a standard US low beam, was used to derive Table 6 , which lists the luminous intensity directed towards the signs for each vehicle type. These calculations assume that both the headlamp beam pattern and the on-the-road headlamp aim is the same and correct for all types of vehicles. (Cobb's ${ }^{(2)}$ data indicate that the headlamps of heavy trucks were generally aimed lower than those of cars. If that were the case for the US situation, then the amount of light reaching the signs from heavy trucks would be lower than the amount calculated here.)

Table 5 Mean horizontal $(x)$ and $(y)$ coordinates $\left({ }^{\circ}\right)$ of angular locations of signs in relation to the headlamp at a viewing distance of $152 \mathrm{~m}$

\begin{tabular}{|c|c|c|c|c|c|c|c|}
\hline \multirow[t]{3}{*}{ Vehicle group } & \multirow[t]{3}{*}{ Lamp } & \multicolumn{6}{|c|}{ Sign position } \\
\hline & & \multicolumn{2}{|c|}{ Left } & \multicolumn{2}{|c|}{ Centre } & \multicolumn{2}{|c|}{ Right } \\
\hline & & $x\left(x^{\circ}\right)$ & $y\left(0^{\circ}\right)$ & $\left.x()^{\circ}\right)$ & $y\left(0^{\circ}\right)$ & $x\left(0^{\circ}\right)$ & $y\left(^{\circ}\right)$ \\
\hline \multirow[t]{2}{*}{ Cars } & Left & -3.45 & 0.57 & 0.22 & 2.06 & 2.50 & 0.57 \\
\hline & Right & -3.88 & 0.57 & -0.22 & 2.06 & 2.08 & 0.57 \\
\hline \multirow[t]{2}{*}{ Light trucks } & Left & -3.42 & 0.52 & 0.24 & 2.00 & 2.53 & 0.52 \\
\hline & Right & -3.90 & 0.52 & -0.24 & 2.00 & 2.05 & 0.52 \\
\hline \multirow[t]{2}{*}{ Heavy zucks } & Left & -3.29 & 0.48 & 0.37 & 1.97 & 2.66 & 0.48 \\
\hline & Right & -4.03 & 0.48 & -0.37 & 1.97 & 1.92 & 0.48 \\
\hline
\end{tabular}

Fis. low beam at viewing distance of $152 \mathrm{~m}$

\begin{tabular}{lllll}
\hline \multirow{2}{*}{ Vehicle group } & Lann & \multicolumn{3}{c}{ Sign position } \\
\cline { 3 - 5 } & & Left & Centre & Right \\
\hline Cars & Left & 522 & 358 & 2085 \\
\multirow{3}{*}{ Light trucks } & Right & 510 & 353 & 2101 \\
\multirow{3}{*}{ Heavy trucks } & Left & 543 & 366 & 2271 \\
\multirow{2}{*}{} & Right & 529 & 357 & 2297 \\
& Left & 565 & 371 & 2395 \\
& Right & 541 & 354 & 2462 \\
\hline
\end{tabular}

(b) Relative amount of reflected light towards the driver: Table 7 lists the observation angles for each sign and each vehicle group. Table 8 presents the interpolated relative retroreflectances for encapsulated lens material, given the observation angles in Table 7 and retroreflectance values in Table 2.

(c) Total light reaching the eyes of the driver: Table 9 takes into account both the differential amount of light impinging on the sign (Table 6) and the differential amount reflected in the particular direction (Table 8 ). The entries in Table 9 were obtained by:

(i) cross-multiplying the information in Table 6 and Table 8 for each lamp

(ii) obtaining the sum of this product for left and right lamps

Table 7 Mean observation angles $(0)$ by vehicle group at a viewing distance of $152 \mathrm{~m}$

\begin{tabular}{lllll}
\hline Vehicle group & Lamp & \multicolumn{3}{c}{ Sign position } \\
\cline { 3 - 5 } & & Left & Centre & Right \\
\hline Cars & Left & 0.199 & 0.266 & 0.217 \\
\multirow{3}{*}{ Light trucks } & Right & 0.463 & 0.430 & 0.396 \\
& Left & 0.329 & 0.355 & 0.343 \\
Heavy trucks & Right & 0.572 & 0.546 & 0.513 \\
& Left & 0.554 & 0.580 & 0.571 \\
& Right & 0.863 & 0.848 & 0.821 \\
\hline
\end{tabular}

Table \& Relative retrorefectuce for encapsulated lens material Sy

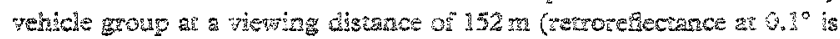
equal to 1 )

\begin{tabular}{lllll} 
Vehicle group & Lamp & \multicolumn{3}{c}{ Sign position } \\
\cline { 3 - 5 } & & Left & Centre & Jight \\
\hline \multirow{2}{*}{ Cars } & Left & 0.876 & 0.832 & 0.847 \\
\multirow{3}{*}{ Light trucks } & Right & 0.399 & 0.456 & 0.517 \\
& Left & 0.644 & 0.594 & 0.617 \\
& Right & 0.243 & 0.275 & 0.322 \\
& Leaty trucks & 0.264 & 0.234 & 0.245 \\
& Right & 0.081 & 0.077 & 0.087 \\
\hline
\end{tabular}


(iii) normalising this sum by setting the corresponding sum for cars to be 1.0 .

\subsection{Consequences for a viewing distance of $305 \mathrm{~m}$}

The calculations for the viewing distance of $305 \mathrm{~m}$ are presented in Tables 10 through 14. These tables are analogous to Tables 5 through 9 for the viewing distance of $152 \mathrm{~m}$.

Table 9 Relative amount of light reaching the eyes of drivers for encapsulated-lens material by vehicle group at a viewing distance of $152 \mathrm{~m}$

\begin{tabular}{llll}
\hline Vehicle group & \multicolumn{3}{c}{ Sign position } \\
\cline { 2 - 4 } & Left & Centre & Right \\
\hline Cars & 1.00 & 1.00 & 1.00 \\
Light trucks & 0.72 & 0.69 & 0.75 \\
Heavy trucks & 0.29 & 0.25 & 0.28 \\
\hline
\end{tabular}

Table 10 Mean horizontal ( $x$ ) and vertical (y) coordinates ( ) of angular locations of signs in relation to the headlamp at a viewing distance of $305 \mathrm{~m}$.

\begin{tabular}{|c|c|c|c|c|c|c|c|}
\hline \multirow[t]{3}{*}{ Vehicle group } & \multirow[t]{3}{*}{ Lamp } & \multicolumn{6}{|c|}{ Sign position } \\
\hline & & \multicolumn{2}{|c|}{ Left } & \multicolumn{2}{|c|}{ Centre } & \multicolumn{2}{|c|}{ Right } \\
\hline & & $x\left(0^{\circ}\right)$ & $y\left(0^{\circ}\right)$ & $x\left(0^{\circ}\right)$ & $y\left(0^{\circ}\right)$ & $x(9)$ & $y(1)$ \\
\hline \multirow[t]{2}{*}{ Cars } & Left & -1.73 & 0.28 & 0.11 & 1.03 & 1.25 & 0.28 \\
\hline & Right & -1.94 & 0.28 & -0.11 & 1.03 & 1.04 & 0.28 \\
\hline \multirow[t]{2}{*}{ Light trucks } & Left & -1.71 & 0.26 & 0.12 & 1.00 & 1.27 & 0.26 \\
\hline & Right & -1.95 & 0.26 & -0.12 & 1.00 & 1.02 & 0.26 \\
\hline \multirow[t]{2}{*}{ Heavy trucks } & Left & -1.65 & 0.24 & 0.19 & 0.98 & 1.33 & 0.24 \\
\hline & Right & -2.02 & 0.24 & -0.19 & 0.98 & 0.96 & 0.24 \\
\hline
\end{tabular}

Table 11 Luminous intensity (cd) directed towards signs from a US low beam at a viewing distance of $305 \mathrm{~m}$

\begin{tabular}{lllll}
\hline \multirow{2}{*}{ Vehicle group } & Lamp & \multicolumn{3}{c}{ Sign position } \\
\cline { 3 - 5 } & & Left & Centre & Right \\
\hline \multirow{2}{*}{ Cars } & Left & 794 & 847 & 3461 \\
\multirow{3}{*}{ Light trucks } & Right & 763 & 792 & 3341 \\
& Left & 816 & 875 & 3653 \\
Heavy trucks & Right & 778 & 810 & 3503 \\
& Left & 841 & 906 & 3811 \\
& Right & 780 & 806 & 3568 \\
\hline
\end{tabular}

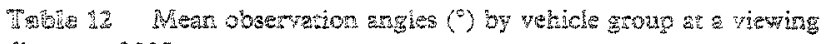
distance of $305 \mathrm{~m}$

\begin{tabular}{lllll}
\hline Vehicle group & Lamp & \multicolumn{3}{c}{ Sign position } \\
\cline { 3 - 5 } & & Left & Centre & Right \\
\hline \multirow{2}{*}{ Cars } & Left & 0.100 & 0.107 & 0.104 \\
Light trucks & Right & 0.221 & 0.213 & 0.205 \\
& Left & 0.165 & 0.172 & 0.169 \\
Heavy trucks & Right & 0.277 & 0.270 & 0.263 \\
& Left & 0.281 & 0.287 & 0.284 \\
& Right & 0.426 & 0.422 & 0.416 \\
\hline
\end{tabular}

Table 13 Relative retroreflectances for encapsulated lens material by vehicle group at a viewing distance of $305 \mathrm{~m}$ (retroreflectance at $0.1^{\circ}$ is equal to 1)

\begin{tabular}{lllll}
\hline Vehicle group & Lamp & \multicolumn{3}{c}{ Sign position } \\
\cline { 3 - 5 } & & Left & Centre & Right \\
\hline \multirow{2}{*}{ Cars } & Left & $\mathbf{1 . 0 0 0}$ & 0.992 & 0.996 \\
\multirow{3}{*}{ Light trucks } & Right & 0.840 & 0.853 & 0.867 \\
& Left & 0.925 & 0.915 & 0.919 \\
Heavy trucks & Right & 0.742 & 0.755 & 0.768 \\
& Left & 0.734 & 0.723 & 0.729 \\
& Right & 0.463 & 0.470 & 0.481 \\
\hline
\end{tabular}

Table 14 Relative amount of light reaching the eyes of drivers for encapsulated lens material by vehicle group at a viewing distance of $305 \mathrm{~m}$

\begin{tabular}{llll}
\hline Vehicle group & \multicolumn{3}{c}{ Sign position } \\
\cline { 2 - 4 } & Left & Centre & Right \\
\hline Cars & 1.00 & 1.00 & 1.00 \\
Light trucks & 0.93 & 0.93 & 0.95 \\
Heavy trucks & 0.68 & 0.68 & 0.71 \\
\hline
\end{tabular}

\section{Discussion}

\subsection{Main findings}

The main findings can be summarised as follows:

(a) At both distances tested, the amount of light reflected to the eyes of truck drivers from retroreflective traffic signs is less than the light reflected to the eyes of car drivers.

(b) This effect is greater for drivers of heavy trucks than light trucks.

(c) This effect is more pronounced at the viewing distance of $152 \mathrm{~m}$ than at $305 \mathrm{~m}$.

(d) This effect is similar for the three sign locations tested (left shoulder, centre, and right shoulder).

\subsection{Implications}

The two viewing distances were selected to represent a reasonable value for sign detection $(305 \mathrm{~m})$ and for sign legibility $(152 \mathrm{~m})$. What are the practical implications of the present findings for detection and legibility of signs? For the viewing distance of $305 \mathrm{~m}$, in the worst cases (centre and left signs), the amount of light reaching a driver of a heavy truck is about $68 \%$ of the light reaching a driver of a car (see Table 14). This represents a drop of glbovit 0.17 log uniss. We used the data of Otson, Bettls, and $\mathrm{Aoki}^{(21)}$ to interpret the effect of such a drop in light on detection distance. The data of Olson at al. ${ }^{(1)}$ show a generally linear relation between $\log$ luminance and detection distance. These dara suggest that a $0.17 \mathrm{log}$ unit drop in light results in a reduction in detection distance of about $30 \mathrm{~m}$, or about $10 \%$ from the assumed detection distance of $305 \mathrm{~m}$.

For the viewing distance of $152 \mathrm{~m}$, in the worst case (centre sign), the amount of light reaching a driver of a heavy truck is only about $25 \%$ of the light reaching a 
driver of a car (see Table 9). This represents a drop of about $0.6 \mathrm{log}$ units. Legibility of signs is affected by both the contrast between the legend and background, as well as the luminances of these two components ${ }^{(12)}$. The effect under consideration-a reduction of light reaching the observer-will have no effect on contrast. Consequently, any effects on legibility would be because of changes in the absolute levels of the legend and background luminances. However, the effect of luminance depends on a variety of factors, including the initial level of luminance, surround luminance, letter size, colours involved, age of the observer (with older observers being more affected), direction of the contrast, and contrast level ${ }^{(12,13)}$. For example, the data of Allen et al. ${ }^{(13)}$ indicate that for positive contrast (light legend on dark background), a reduction in the legend luminance from $6.8 \mathrm{~cd} \mathrm{~m}^{-2}$ to $1.7 \mathrm{~cd} \mathrm{~m}^{-2}$ (a drop of about $0.6 \mathrm{log}$ units) would reduce correct identification (of three-letter words) from about $55 \%$ to about $35 \%$ (a drop of about $36 \%$ from the baseline performance) for legend-to-background contrast of near $100 \%$, and from about $45 \%$ to $35 \%$ (a drop of about $22 \%$ from the baseline performance) for contrast of $75 \%$. However, at high initial luminances, a drop of $0.6 \mathrm{log}$ units would produce smaller or no reductions in legibility.

In conclusion, this analysis suggests that the effect of the increased eye height of truck drivers could have a major effect on the legibility of retroreflective traffic signs, but only a modest effect on their detection. Reduced observation angles for truck drivers or inherently more efficient retroreflective sign materials would alleviate the potential problems.

\section{Acknowledgements}

Appreciation is extended to the members of The University of Michigan Industry Affiliation Program for Human Factors in Transportation Safety for support of this research. The current members are Bosch, Carello Lighting, Donnelly, Ford (Plastic and Trim Products Division), GM (Inland Fisher Guide Division), GTE Products, Ichikoh Industries, Koito Manufacturing, Libbey-Owens-Ford, Muth Advanced Technologies, Philips Lighting, Stanley Electric, and $3 \mathrm{M}$.

Special thanks to to $\mathrm{Mr} \mathrm{J} \mathrm{Cobb}$ from the Transport and Road Research Laboratory (TRRL) in Crowthorne, England, for making available to us from his survey the raw data on seated eye heights and headlamp mounting heights. The present research would not have been possible without those data. Appreciation is also extended to Mr Norbert Johnson and Mr John Jones (both from 3M) for providing photometric information on traffic sign materials and technical advice.

\section{References}

1 Sivak $M$ and Ensing $M$ Human factors considerations in the design of truck lighting, signaling, and rearview mirrors Technical Report UMTRI-91-3 (Ann Arbor, MI: Universiry of Michigan Transportation Research Insitute) (1991)

2 Cobb J Roadside survey of vehicie lighting 1989 Research Report 290 (Crowthorne, UK: Transport and Road Research Laboratory) (1990)

3 Cunagin $W$ and Abrahamson $T$ Driver eye height: a field study ITE $\mathcal{Y} .49(5) 34-46(1979)$

4 Farber E 1 Driver eye-height trends and sight distance on vertical curves Transportation Research Record 855 27-33 (1982)

5 Olson P L, Cleveland D E, Fancher P S, Kostyniuk L P and Schneider L W Parameters affecting stopping sight distance NCHRP Report 270 (Washington DC: Transportation Research Board) (1983)

6 Transportation Code of federal regulations Title 49 Parts 400 to 999 Revised 1 October, 1990 (Washington DC: Office of the Federal Register) (1990)

7 Johnson $\mathrm{N} \mathrm{L}$ Accuracy in photometry of retroreflectors Proc. Soc. Photo-Optical Instrumentation Engineers 196 136-146 (1979)

8 Recommendations for surface colours for visual signalling Publication No. 39-2 (Vienna: Commission Internationale de 1'Eclairage) (1983)

9 Woitman $\mathrm{HI}$ and Szczech T I Sign luminance as methodology for matching driver needs, roadway variables, and signing materials Transportation Research Record $121321-26$ (1989)

10 Sivak $M$, Gellatly $A$ and Flannagan $M$ Minimum light above horizontal of lozy-beam headlamps for nightime legibility of traffic signs Technical Report UMTRI-91-3 (Ann Arbor, MI: University of Michigan Transportation Research Institute) (1991)

11 Olson $\mathrm{PL}$, Battle $\mathrm{D} \mathrm{S}$ and Aoki $\mathrm{T}$ The detection distance of highway signs as a function of color and photometric properties Technical Report UMTRI-89-36 (Ann Arbor, MI: University of Michigan Transportation Research Institute) (1989)

12 Olson $\mathrm{PL}$, Sivak $\mathrm{M}$ and Egan J C Variables influencing the righttime legibility of highway signs Technical Report UMTRI-8336 (Ann Arbor, MI: University of Michigan Transportation Research lnstitute) (1983)

13 Allen $T M$, Dyer $F N$, Smith $G M$ and Janson $M H$ Luminance requirements for illuminated signs Highway Research Record 179 $16-37(1967)$ 